\title{
STUDY OF CORRELATION BETWEEN THE CYTOLOGICAL AND HISTOPATHOLOGICAL FINDINGS OF NON-NEOPLASTIC AND NEOPLASTIC BREAST LESION
}

\section{Dr Rina Kumari}

Dr Deepak Kumar*

\section{Senior Resident, Department of Pathology, J L N medical college Bhagalpur} Associate Professor \& HOD, Department of Pathology, J L N medical college Bhagalpur *Corresponding Author

ABSTRACT Background: Study of correlation between the cytology and histopathological findings of nonneoplastic and neoplastic breast lesion.

Method : The present prospective observational study was conducated in jlnmc for a period of 6 months from 15th April to 14th Sept. we had studied 100 cases and specimens were received in histopathological section of our department.Gross examination of speciemens did followed by fixation, proper sampling and tissue processing.

Result: Total 100 cases were studied of which 38 cases were nonneoplastic, 36 cases were benign neoplastic lesion, 5 cases borderline and 21 cases were malignant. Over all fibroadenoma was most common benign lesion with 18 cases. Invasive ductal carcinoma nos were most common malignant lesion followed by lobular carcinoma.malignant phylloid was the most common nonepithelial malignancy.

Conclusion: Histology remains gold standard for diagnosis of breast lesion

KEYWORDS : Histopathology ,Nonneoplastic, Neoplastic

\section{INTRODUCTION}

Breast is well developed superficially located organ in female and in male rudimentary throughtout the life. Breast is hormone sensitive organ especially to estrogen and progesterone and site of broad array of pathological changes. Due to advance imaging techniques and increase use of fnac have greatly assisted the preoperative evalution of breast lesion, but histopathology remains gold standard for diagnosis of breast lesion.

Benign lesions are more common than malignant lesion. Presently breast cancer is the most common female malignancy worldwide. But due to public awareness, in India breast cancer is second most common cancer due to increasing public awareness, Benign or malignant lesion presenting as lump.

\section{METHOD}

The present prospective study was carried out in department of pathology. Total 200 patients of all ages and sexes those presented with breast lumps were included in study. A working diagnosis was arrived at by analysis of history, clinical examination and FNAC, following which lump was received for histopathological examination as lumpectomy, biopsy MRM into $10 \%$ formalin.

\section{RESULT}

Total 100 cases of breast lesion were observed in which 75 cases were benign, 4 cases were border line(suspicion of malignancy) and 21 cases were malignant. The lesion were categorised into nonneoplastic and neoplastic lesions. Neoplastic lesions were further divided into benign and malignant lesion. Age of the patients of my study was 20- 75 yrs. Benign lesion more commonly 2- 4 decade of life while malignancies occurred after $5^{\text {th }}$ decade of life but few cases of malignancy were 35- 40 yrs (3cases). Of the 200 pts, 195 were females and 8 were males. Left breast $(60 \%)$ was more commonly involve than right breast(35\%).Bilateral breast were involved in $5 \%$ of cases. Majority of breast lesions were located in upper outer quadrant followed by upper inner quadrant. While few no of cases involved breast diffusely, multipe quadrant were in involved in $8 \%$ of cases.

Fibrocystic ds is most common nonneoplstic lesion and fibroadenoma is the most common neoplastic lesion. Overall fibroadenoma is the most common lesion. Total 21 malignant cases were observed in which most common was ductal carcinoma nos type followed by lobular ca. In nonepithelial malignancy, malignant phylloid is most common.

\section{DISCUSSION}

The main aims of our studied were to know percentage of various types of breast lesions, age and sex distribution of lesions and study of various risk factors associated with breast carcinoma.

Benign breast lesions were more common than malignant lesion. Fibroadenoma was most common beningn lesion followed by fibrocystic ds. Similar findings were reported by Haque $A$ et al and Gupta Jc et al . In our study maximum lesion of cases were present in 2l-40 yrs of age. All the pts were present breast lump, similar finding were observed by vijayabharathi et al(2015) [7], Sandhu et al (2010)[11] .

Proportion of males cases in various studies varies from $4 \%$ to $8 \%$,in our study it was $3.9 \%$.female proportion varies from 91.7 to $98.6 \%$, in our study it was $96.1 \%$ which well correlated with other similar studies. Total 5 cases were studied in which gynaecomastia(2), lipoma(1), fibroadenoma (1) and breast carcinoma(1).

I studied 10 cases of mastitis in which 5 cases were acute mastitis, 10 cases were in puerperal period and 3 cases were in non puerperal period. Breast abscess were formed in $7.5 \%$ in my survey .Haque $A$ et al and gupta jc al reported $4 \%$ and $1.3 \%$.Age of the pts of breast abscess were 18-55 yrs but Haque $\bar{A}$ et al. noticed breast abscess 16- 65 yrs. Breast abscess that was develop in puerperal period generally have better prognosis than nonpuerperal abscess which need long treatment and higher antibiotics. Risk factors for development of non puerperal breast abscess were black race, smoking, diabetic, obesity and tobacco.

Most of the cases of breast abscess were drained and minority cases biopsied. Similar condition was seen by Siddigui et al.

Total21 (21\%) cases of malignant breast lesion were studied of which $19(19.5 \%)$ cases were carcinoma and $2(1.5 \%)$ cases were non epithelial malignant tumor. Haque et al reported $48 \%$ cases of breast carcinoma.In my studied maximum cases were reported in the age group of $40-60$ yrs but Jemal $A$ et al reported $41-50$ yrs.

There were 21 cases of breast carcinoma of which 15(74\%) \begin{tabular}{l|l} 
Submitted : $16^{\text {th }}$ August,2019 & Accepted : 17 \\
\hline
\end{tabular} 
cases were ductal carcinoma nos type.While Mudholkar et al (2012) (11),Dayanand et al (2015)(20) and Imbrahim et al (2015) (10) at $88 \% \quad 85.5 \%$ and 59.5).Incidence of phylloid tumors were $2 \%$ in present study as compare to Dayanand et al (2015)(20) and Ibrahim et al(2015)(10) who reported it in $7.6 \%$ and $4.8 \%$.

5 cases of lobular carcinoma, 2 cases of medullary carcinoma, 1 case of tubular carcinoma and 1 cases of malignant phylloid were diagnosed.

\section{CONCLUSION}

Overall nonneoplastic lesions were more common than neoplastic lesion.But fibroadenomas were most common breast lesion. In nonneoplastic lesion fibrocystic disease were most common lesion followed by breast abscess and acute mastitis. Beningn breast lesion were more common in $2^{\text {nd }}, 3^{\text {rd }}$ and $4^{\text {th }}$ decade of life. Risk of malignancy increases with age. Most of malignancies were seen in $5^{\text {th }}, 6^{\text {th }}$ and $7^{\text {th }}$ decade of life, but slight increase in incidence of breast carcinoma b/w 35 to $40 \mathrm{yrs}$ of life. Among malignant lesion ductal carcinomas nos type were the most common malignancy diagnosed on histopathology. Risk factors for breast lesions were nulliparity, use of ocp, obesity, family history radition exposure, early menarche and late menopause. Histopsthological study plays very important role in diagnosis of breast lesion lesion and hencet/tment and prognosis.

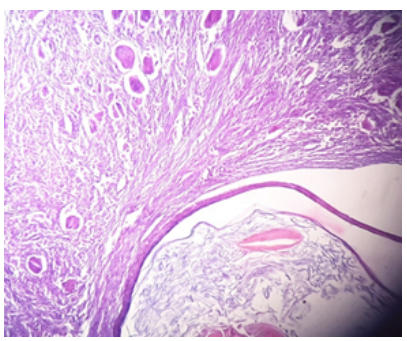

\section{EPIDERMOID CYST OF BREAST}

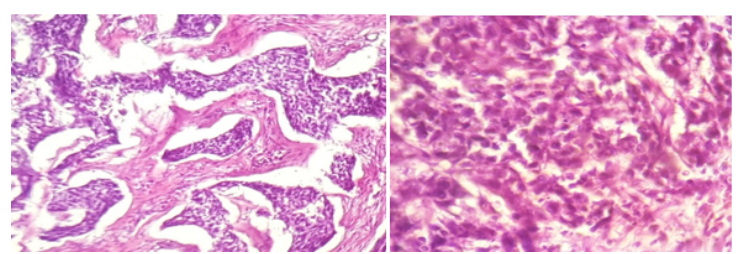

Low and high power view of ductal carcinoma of breast

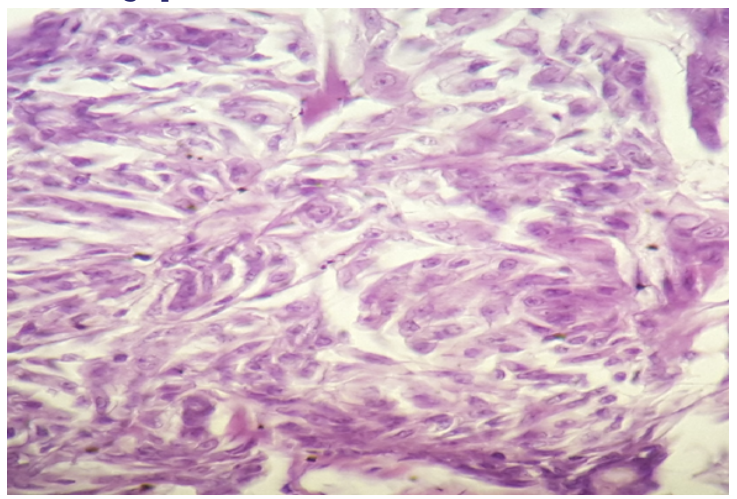

\section{FIBROSARCOMA OF BREAST}

\section{REFERENCES}

1. SulhyanKR, AnvikarAR, Mujawar IM, TiwariH.Histopathologicals study of breast lesions.IJMSR Rev.2017;5(01):32-41.

2. RajuGC, JankeyN, NarayansinghV .Breast disease in young west Indian women :ananalysis of 1051 cases. PostgradMedJ. 1985;61(721):977-8.

3. HaqueR,Tyagi SP, Khan MH, Gahlaut YVS.Breast lesion A clinicopathological study of 200 cases of breast lumps. Ind J Surg.1980;42:419-25.

4. Shabtai M Saavedra-Malinger PShabtai EL,Rosin D,Kuriansky J,RavidMagido $\mathrm{M}$ et al.Fibroadenoma of the breast:Analysis of associated pathological entities-A different risk marker in different age groups for concurrent breast cancer.IMAJ.2001:3813-7.

5. Aslam HM, Saleem S, Shaikh AR, Shahid N, Mughal A, Umah R. Clinicopathological profile of patients with breast diseases; Diagnostic Pathology 2013; 77(8):1-6.

6. Vijayabharathi I, Bhagyalakshmi A, Prasad RJ, SSK. Prospective Study of Cyto Histopathological Correlation of Breast Lesions. J Evid based Med Healthcare. 2015; 2(24):3577-86

7. Malik R, Bharadwaj VK. Breast lesions in young females-a 20-year study for significance of early recognition. Indian journal of pathology \& microbiology. 2003 Oct; 46(4):559-62.

8. Rathi M, Khalid M, Budania SK, Mittal A, Verma N. A clinicopathologic study of various breast lesions with cytohistological correlation. Muller Journal of Medical Sciences and Research. 2015; 6(1):16-22.

9. Watt-Boolsen S, Rasmussen NR, Blichert-Toft M. Primary periareolar abscess in the nonlactating breast: risk of recurrence. Am J Surg 1987; 153(6): 571-573.

10. Shetty MK, Shah YP, Sharman RS. Prospective evaluation of the value of combined mammographic and sonographic assessment in patients with palpable abnormalities of the breast. Journal of Ultrasound in Medicine 2003;22(3):263-268

11. Carter CL, Corle DK, Micozzi MS, Schatzkin A, Taylor PR. A prospective study of the development of breast cancer in 16,692 women with benign breast disease. Am J Epidemiol 1988; 128:467-477 